\title{
Treefrog lateral line as a mean of individual identification through visual and software assisted methodologies
}

\author{
Mi Yeon Kim ${ }^{1}$, Amaël Borzée ${ }^{1,2}$, Jun Young Kim ${ }^{1}$ and Yikweon Jang ${ }^{1,3^{*}}$ (D)
}

\begin{abstract}
Background: Ecological research often requires monitoring of a specific individual over an extended period of time. To enable non-invasive re-identification, consistent external marking is required. Treefrogs possess lateral lines for crypticity. While these patterns decrease predator detection, they also are individual specific patterns. In this study, we tested the use of lateral lines in captive and wild populations of Dryophytes japonicus as natural markers for individual identification. For the purpose of the study, the results of visual and software assisted identifications were compared.

Results: In normalized laboratory conditions, a visual individual identification method resulted in a 0.00 rate of false-negative identification (RFNI) and a 0.0068 rate of false-positive identification (RFPI), whereas Wild-ID resulted in RFNI $=0.25$ and RFNI $=0.00$. In the wild, female and male data sets were tested. For both data sets, visual identification resulted in RFNI and RFPI of 0.00 , whereas the RFNI was 1.0 and RFPI was 0.00 with Wild-ID. Wild-ID did not perform as well as visual identification methods and had low scores for matching photographs. The matching scores were significantly correlated with the continuity of the type of camera used in the field.
\end{abstract}

Conclusions: We provide clear methodological guidelines for photographic identification of D. japonicus using their lateral lines. We also recommend the use of Wild-ID as a supplemental tool rather the principal identification method when analyzing large datasets.

Keywords: Lateral lines, Photographic individual identification, Treefrog, Wild-ID, Visual identification, Software assisted identification

\section{Background}

Individual identification of animal is critical in behavioral ecology. Numerous research subjects such as fitness, life history, territoriality, social behavior, and long-term monitoring require repeated identification of individuals. Traditionally, individual identification was conducted through uniquely applied markings (Amstrup et al. 2010). Markings can be natural or artificial. For amphibians, traditional marking techniques include toe-clipping, branding, tattooing, subcutaneous elastomer injections, and subcutaneous pit tags (Ferner 1979, Donnelly et al., 1994). One of the

\footnotetext{
*Correspondence: jangy@ewha.ac.kr

'Department of Life Sciences and Division of EcoScience, Ewha Womans University, Seoul 03760, Republic of Korea

${ }^{3}$ Interdisciplinary Program of EcoCreative, Ewha Womans University, Seoul 03760, Republic of Korea

Full list of author information is available at the end of the article
}

most frequently used method is toe-clipping because of its easy and inexpensive use (Donnelly et al., 1994, Waichman 1992). However, its use is currently debated as an invasive method, potentially causing infections and altering behaviors, especially for small species like hylids (Clarke 1972, Golay and Durrer 1994, Lemckert 1996, Waddle et al. 2008, Guimaraes et al. 2014). As a result, the environmental administration of the Federative Republic of Brazil has considered a ban on toe-clipping (Corrêa 2013). In contrast, the use of natural markers in photographic identification method (PIM) has gained popularity because of technological advances, being relatively inexpensive, and its noninvasive quality.

Amphibians are under aggravated threats (Stuart et al. 2004, Wake 2012), and the use of individual natural markings in PIM is a popular alternative method for noninvasive individual identification. To date, herpetological 
PIM has been used to identify individuals from a wide range of species with unique natural patterns, including frogs (Lama et al. 2011), toads (Elgue et al. 2014), salamanders (Church et al. 2007, Gamble et al. 2008), geckos (Knox et al. 2012), and leatherback turtles (Dermochelys coriacea; McDonald et al. 1996) among others.

The use of PIM with dorsal patterns of adult greeneyed treefrogs (Litoria genimaculata) as a natural marker was successfully demonstrated in the wild (Kenyon et al. 2009). The natural markers commonly used for hylid species are dorsal, ventral, and leg patterns. These patterns are stable over time, with the exception of juveniles, and are thus appropriate for PIM studies (Bolger et al. 2012). In contrast, colors are less stable and are not reliable markers.

More recently, computer-assisted PIM is used in an expanding number of mark and recapture studies throughout a broad range of species. When the image catalog for previous captures are large, the visual inspection becomes not only time consuming but unreliable. Therefore, advances on digital image analysis tools and pattern recognition algorithms play a significant role in the development and spreading the use of PIM (Bolger et al. 2012). However, the efficiency and accuracy of PIM and photographic analysis tool should always be tested before being implemented.

Here, we tested the use of lateral lines as natural markers for individual identification of wild and captive populations of Dryophytes japonicus. PIM was conducted by both visual identification method and a computerized assisted photograph-matching program: Wild-ID. Our goals were to assess the use of $D$. japonicus lateral line as a natural marker in individual identification, assess the validity of our methodology in a scientific research setting, provide protocols for the collection of photographic data, and demonstrate limitations of Wild-ID in identifying an individual $D$. japonicus using its lateral line as a natural marker.

\section{Methods}

The species used for this study was Dryophytes japonicus, previously assigned to Hyla japonica (Duellman et al., 2016), and recognized as synonymous to D. ussuriensis and D. stepheni (Dufresnes et al. 2016). The species is present in North East Asia and is the most common amphibian species breeding in rice paddies in the Republic of Korea (Roh et al. 2014). The photographic data for this study were collected over two independent periods, once in the laboratory and once in the field. In photographs, a lateral line was defined as starting from the posterior tip of the tympanum and finishing at the skin folds leading to the rear legs. For each individual, photographs were taken in series while the individual was held presenting its dextral lateral line parallel to the camera. Care was taken to including the totality of the lateral line on the picture by carefully holding the individual's legs between thumb and index finger while supporting the body with the thumb (Fig. 1a), and thus preventing the frogs from sitting naturally and bending its legs.

Before using the photographs for PIM, the best quality photograph with the lateral line clearly visible was selected for each individual frog. The selected photographs were then cropped such that the totality of the lateral line was included with a minimum amount of background (Fig. 1b). The cropping process excluded the majority of the background to remove external cues such as frog legs or dorsal patterns and in some cases the fingertips of the researcher.

The processed photographs were analyzed twice, once with visual identification and the other with PIM. For the visual identification method, a group of participants identified matching lateral lines without a computerized matching program. For PIM, a group of separate participants used Wild-ID to identify identical lateral lines. The computerized matching program Wild-ID 1.0 (Version 1.0; Dartmouth College; Hanover, New Hampshire, USA) used in this study is a pattern extraction matching program for photographs (Bolger et al. 2012). The software employs the Scale Invariant Feature Transform (SIFT) operator, and for each photograph, it returns the 20 most similar photograph in rank according to the matching score of similarity $(1.0=$ $100 \%$ similarity, $0.0=0 \%$ similarity). All photographs were

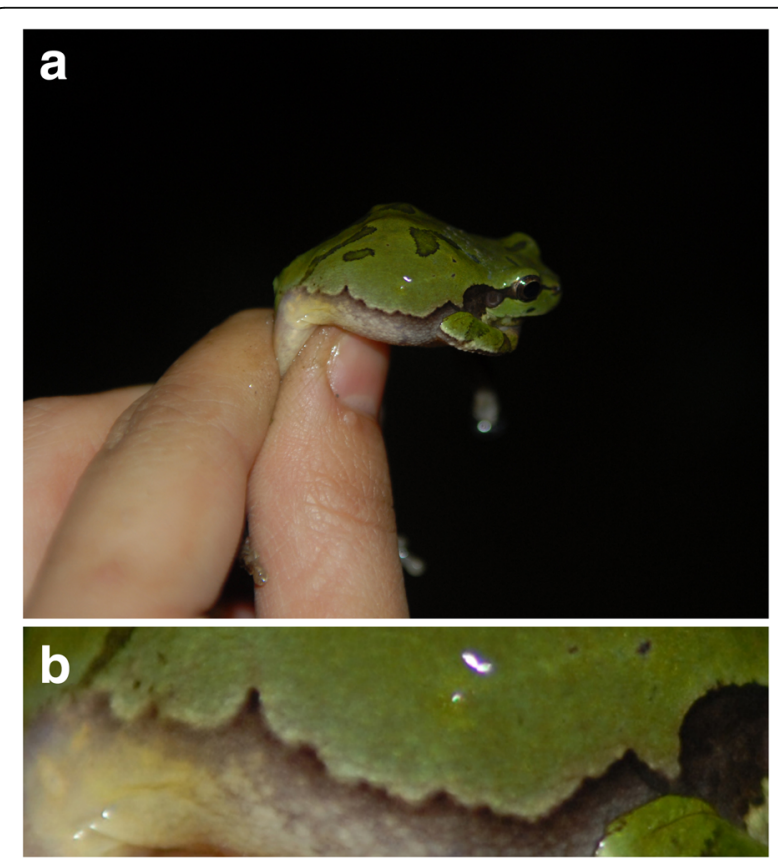

Fig. 1 Photographic illustration on how to take a photograph of the lateral line of an individual frog to be used for the PIM. a How frogs are held to show the totality of lateral line in the photograph. $\mathbf{b}$ Cropped photograph with the lateral line and with minimum amount of background to be used for the analysis 
processed by Wild-ID according to the suggested procedure (Boldger et al. 2012).

Before looking at the dataset of the study, all participants were given a set of ten randomly selected photographs with two matching individuals and were asked to identify them either with or without a computerized matching program. All participants in this study were field trained, familiar with frog patterns, and without prior interaction with the photographs used in this study.

\section{Photographs of lab-raised individuals}

In order to conduct the photographic identification in laboratory conditions, $27 \mathrm{D}$. japonicus were caught in the city of Paju, Republic of Korea $\left(37.7519^{\circ} \mathrm{N}, 126.7253^{\circ} \mathrm{E}\right)$, in September 2013. Individuals were subsequently housed in cylindrical PVC boxes (15 cm diameter $\times 15 \mathrm{~cm}$ high), with vertical aerations until November 2013. Individuals were photographed every 14 days, with a tripod mounted camera (DSLR, NIKON D200 and AF-S NIKOR 17-

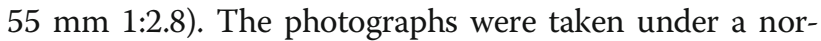
malized light condition averaged at $52.3 \mathrm{~lx}$.

\section{Analysis of lab photographs}

A set of photographs for 27 different $D$. japonicus and one matching photograph of one individual taken at two different dates were formatted for the analysis $(n=28)$. This allows for true individual match known to the researcher. For the analysis, eight participants were given the set of photographs and were asked to visually identify matching lateral lines. Eight different participants were then asked to identify identical individuals through Wild-ID.

\section{Photographs of field-caught individuals}

The second data set used was acquired during weekly surveys throughout the breeding season of $D$. japonicus, from 18 April to 3 July 2014 (for the full protocol, see Kim 2015). During each survey, every individual seen was caught and photographed for its lateral pattern using three different types of methods: (1) a photo-box that provided normalized setting with Samsung compact cameras (ES95; Samsung, People's Republic of China) and illuminated by mini motion light (average $=146 \mathrm{~lx}$; Koninklijke Philips Electronics N.V., People's Republic of China) covered with neutral gray paper sheets; 2) Nikon D200 and mounted lens AF-S NIKKOR 17-55 mm 1:2.8 with its own momentary flash (average $=395 \mathrm{~lx}$ ), and (3) Sony digital camera (Alpha NEX-C3; Sony, Thailand) with its own flash (average $=148 \mathrm{~lx}$ ).

\section{Analysis of field photographs}

For the purpose of this study, photographs of all females caught throughout all the weekly surveys $(n=75)$ were used as the first dataset, while only males caught on 11 June 2014 and 18 June 2014 $(n=318)$ were used as the second dataset. For the analysis, two participants were given both datasets and asked to visually identify matching lateral lines. Then, two different participants were given the same two datasets and were asked to identify identical lateral lines using Wild-ID.

\section{Performance of identification method}

To evaluate the identification rate of both visual identification and PIM, we calculated the rate of false-negative identification (RFNI: failure to match two images of the same individual; RFNI = number of false-negative identification/number of identification attempts) and the rate of false-positive identification (RFPI: match of two images of different individuals; RFPI = number of false-positive identification/number of identification attempts).

Finally, the photographs from the recaptured males were run alone into Wild-ID for an ad-hoc test to compare matching scores and camera types between recaptures. The matching score provided by Wild-ID for matched photographs represents the relative closeness of the match, with 1.0 being the highest match value. The resulting scores were correlated with the continuity of the type of camera used (Table 1). The statistical analysis were run with SPSS v21.0 (SPSS, Inc., Chicago, IL, USA).

Table 1 Matching scores $(1.0 \geq n \geq 0.0)$ given by Wild-ID for recaptured males for the two consecutive weeks with the type of camera used to take the lateral line photograph for each field date

\begin{tabular}{lll}
\hline Matching score & $\begin{array}{l}\text { Camera used in } \\
\text { 11 June 2014 }\end{array}$ & $\begin{array}{l}\text { Camera used in } \\
18 \text { June 2014 }\end{array}$ \\
\hline 0.000000 & Samsung ES95 & Samsung ES95 \\
0.000000 & Samsung ES95 & Samsung ES95 \\
0.000000 & Samsung ES95 & Samsung ES95 \\
0.000000 & Samsung ES95 & Samsung ES95 \\
0.000000 & Samsung ES95 & NIKON D200 \\
0.000000 & Sony Alpha NEX-C3 & Samsung ES95 \\
0.000000 & Sony Alpha NEX-C3 & Sony Alpha NEX-C3 \\
0.000003 & Sony Alpha NEX-C3 & NIKON D200 \\
0.000003 & Sony Alpha NEX-C3 & NIKON D200 \\
0.000003 & Sony Alpha NEX-C3 & NIKON D200 \\
0.000000 & NIKON D200 & Samsung ES95 \\
0.000000 & NIKON D200 & Samsung ES95 \\
0.000000 & NIKON D200 & Samsung ES95 \\
0.000000 & NIKON D200 & Samsung ES95 \\
0.000000 & NIKON D200 & Samsung ES95 \\
0.000000 & NIKON D200 & Samsung ES95 \\
0.000004 & NIKON D200 & Samsung ES95 \\
0.131066 & NIKON D200 & NIKON D200 \\
\hline
\end{tabular}




\section{Results}

\section{Photographs of lab-raised individuals}

The visual identification method resulted in eight positive matches, with a RFNI of 0.00 and 21 false-positive matches with a RFPI of 0.0068 . The photographic analysis using Wild-ID resulted in six positive matches with RFNI $=0.25$ and no false-positive matches with RFNI $=$ 0.00 . The matching pair found through Wild-ID received a matching score of 0.072732 , with the picture ranked first from the list of 20 potential matches.

\section{Photographs of field caught individuals}

The visual identification for the female data set had a RFNI of 0.00 and RFPI of 0.00 , whereas the RFNI was 1.00 and RFPI was 0.00 through Wild-ID. An ad-hoc run on Wild-ID to assess the score given by the software for a match of the two photographs returned a value of 0.000002 , a score too low to be considered as a potential match in Wild-ID. It was observed that when matching scores were low for all photographs, the 20 potential matches given by Wild-ID followed the order of input in the database folder. The visual identification of photographs of males from the two consecutive weeks identified 18 recaptures with RFNI of 0.00 and RFPI of 0.00 . Using Wild-ID, no recaptured individuals were identified, resulting in RFNI $=1.0$ and $\mathrm{RFPI}=0.0$.

When comparing the continuity in the type of camera used and the best scores, the highest score was obtained for the recapture photographed both times with the DSLR camera (0.131066), whereas every other combination of camera type had 0.000004 for highest match score (Table 1). The correlation between repetition in camera type and scores was significant $(R=-0.67, n=$ $18, p=0.014)$, but it was not for camera type used for one of the two captures (first capture: $R=0.24, n=18, p$ $=0.332$; second capture: $R=-0.27, n=18, p=0.914$ ).

\section{Discussion}

Despite their popularity, the computerized photographic identification methods are difficult to use for identification of individual treefrogs based on their lateral lines. However, and especially for small datasets, using lateral lines as natural markers to identify individuals is possible through visual inspection.

One of the limitations of computer-assisted photographic identification is the production of misidentification errors that can severely bias studies (Lukacs and Burnham 2005, Yoshizaki et al. 2009). It is thus important to set an estimate of misidentification error as a step in evaluating the efficacy of computer-assisted photographic identification (Hastings et al. 2008). In this study, both false-negative identification and falsepositive identification occurred, but more importantly, the identical individual photographs were not given as a potential match by the program.

Wild-ID is a pattern-matching program designed to find and extract distinctive image features (Bolger et al. 2012). Ever since the release of the program, it has been used for many species of animals, the majority of them with spots (Bolger et al. 2012, Bendik et al. 2013, Elgue et al. 2014, Dala-Corte et al. 2016). This study is uncommon in that it is testing the program on a linear pattern. Therefore, the result of this experiment could be an indication of the limitation on using Wild-ID with different pattern types.

The scores for Wild-ID were low, resulting in the absence of matching individuals in the ranked potential matches, which directly affected the rate of individual identification. The results of this study show that the matching scores were affected by the type of camera that was used to take photographs. The only high matching score in this study originated from photographs taken with the DSLR camera, providing high-quality photographs (Table 1). The quality of the photograph is an important factor in the successful use of Wild-ID, which means that high-end cameras should be used to obtain optimum quality photographs.

Despite the inability of Wild-ID to get matches, the software can be used to assist with very large datasets. Wild-ID gives 20 photographs as a potential matches, and therefore, if only 20 photographs are fed to Wild-ID at a time, the software can be used as a facilitating comparison tool, rather than a software picking matches from a database.

The visual identification method was successful in individual identification despite the dorsal coloration change in accordance with surrounding conditions (Choi and Jang 2014, Kang et al. 2016). The longest period between taking two photographs that were identified as matched by participants was 35 days. This suggests a possibility of using PIM in long-term ecological research of D. japonicus.

Our results also highlight the importance of normalized conditions. Taking pictures in laboratory conditions improved matches. Despite our efforts, it is difficult to maintain the same standard in the field. Finally, this experiment relied on photographing the lateral line of individuals, but focusing on other permanent morphological cues such as leg stripes may provide different results.

\section{Conclusions}

This study tested the use of lateral lines of $D$. japonicus in photographic individual identification and compared the performance of visual identification method and software assisted identification method (Wild-ID). The results demonstrate that lateral lines of D. japonicus could be used as a natural marker for individual identification; however, only visual identification method was proven to be reliable for identifying recaptured individuals. 
The suggested key guidelines for using lateral lines of treefrog for photographic identification are as follows: 1 . The entire lateral line of an individual should be captured through holding its legs back, 2. Constant high quality of photograph is crucial in getting the best results in identification of individuals and 3. In analyzing the data, we suggest use of visual identification method with using Wild-ID as a supplementary tool.

\section{Abbreviation}

PIM: Photographic identification method

\section{Acknowledgements}

We are grateful to Dasom Lee, Hyojeong Han, Donggeun Lee, Sunmin Oh, and Euncheong Sin for their help and commitment during field, and to Dami Jeong for access to the site in Ododong. We would also like to appreciate anonymous reviewers for their valuable comments on the manuscript.

\section{Funding}

This work was supported financially by a grant from Rural Development Administration (PJ012285) to YJ.

\section{Availability of data and materials}

The datasets are available from the corresponding author on a request.

\section{Authors' contributions}

MK carried out the study, performed the analysis, and wrote the manuscript. JK conducted the field data collection as well as part of PIM. AB participated in the design of the study, analyzed data, and wrote/reviewed the manuscript. YK contributed to draft the manuscript. All authors read and approved the final manuscript.

\section{Ethics approval and consent to participate}

The experiments in this study comply with the current law of the Republic of Korea (Ministry of Environment Permit Number: 2013-16).

\section{Consent for publication}

Not applicable.

\section{Competing interests}

The authors declare that they have no competing interest.

\section{Publisher's Note}

Springer Nature remains neutral with regard to jurisdictional claims in published maps and institutional affiliations.

\section{Author details}

'Department of Life Sciences and Division of EcoScience, Ewha Womans University, Seoul 03760, Republic of Korea. ${ }^{2}$ Laboratory of Behavioral Ecology and Evolution, School of Biological Sciences, Seoul National University, Seoul 08826, Republic of Korea. ${ }^{3}$ Interdisciplinary Program of EcoCreative, Ewha Womans University, Seoul 03760, Republic of Korea.

Received: 27 June 2017 Accepted: 7 December 2017

Published online: 19 December 2017

\section{References}

Amstrup SC, McDonald TL, Manly BF, editors. Handbook of capture-recapture analysis. Princeton: Princeton University Press; 2010.

Bendik, N. F., Morrison, T. A., Gluesenkamp, A. G., Sanders, M. S., \& O'Donnell, L. J. (2013). Computer-assisted photo identification outperforms visible implant elastomers in an endangered salamander, Eurycea tonkawae. PLoS One, 8(3), e59424.

Bolger, D. T., Morrison, T. A., Vance, B., Lee, D., \& Farid, H. (2012). A computerassisted system for photographic mark-recapture analysis. Methods in Ecology and Evolution, 3(5), 813-822.
Choi, N., Jang, Y (2014). Background matching by means of dorsal color change in treefrog populations (Hyla japonica). Journal of Experimental Zoology. Part A, Ecological Genetics and Physiology, 321, 108-118.

Church, D. R., Bailey, L. L., Wilbur, H. M., Kendall, W. L., \& Hines, J. E. (2007). Iteroparity in the variable environment of the salamander Ambystoma tigrinum. Ecology, 88, 891-903.

Clarke, R. D (1972). The effect of toe clipping on survival in Fowler's toad (Bufo woodhousei fowleri). Copeia, 1, 182-185.

Corrêa, D. T. (2013). Population declines: toe-clipping vital to amphibian research. Nature, 493, 305-305.

Dala-Corte, R. B., Moschetta, J. B., \& Becker, F. G. (2016). Photo-identification as a technique for recognition of individual fish: a test with the freshwater armored catfish Rineloricaria aequalicuspis Reis \& Cardoso, 2001 (Siluriformes: Loricariidae). Neotrop Ichthyol., 14(1), e150074.

Donnelly, M. A., Guyer, C., Juterbock, J. E., \& Alford, R. A. (1994). Techniques for marking amphibians. In: Heyer, R., Donnelly, M. A., Foster, M., \& Mcdiarmid, R., editors. (2004). Measuring and monitoring biological diversity: Standard methods for amphibians, pp 277-284. Washinton, DC: Smithsonian Institution Press.

Duellman, W. E., Marion, A. B., Hedges, S. B (2016). Phylogenetics, classification, and biogeography of the treefrogs (Amphibia: Anura: Arboranae). Zootaxa, 4104, 1-109.

Dufresnes, C., Litvinchuk, S. N., Borzée, A., Jang, Y., Li, J-T., Miura, I., Perrin, N., Stöck, M (2016). Phylogeography reveals an ancient cryptic radiation in East-Asian tree frogs (Hyla japonica group) and complex relationships between continental and island lineages. BMC Evolutionary Biology, 16, 253

Elgue, E., Pereira, G., Achaval-Coppes, F., Maneyro, R (2014). Validity of photoidentification technique to analyze natural markings in Melanophryniscus montevidensis (Anura: Bufonidae). Phyllomedusa: Journal of Herpetology, 13(1), 59-66.

Ferner, J. W. (1979). A review of marking techniques for amphibians and reptiles. Society for the Study of Amphibians and Reptiles, Herpetol Circ., 9, 1-41.

Gamble, L., Ravela, S., \& McGarigal, K. (2008). Multi-scale features for identifying individuals in large biological databases: an application of pattern recognition technology to the marbled salamander Ambystoma opacum. Journal of Applied Ecology, 45, 170-180.

Golay, N., Durrer, H (1994). Inflammation due to toe-clipping in natterjack toads (Bufo calamita). Amphibia-Reptilia, 15, 81-83.

Guimaraes, M., Correa, D. T., Filho, S. S., Oliveira, T. A., Doherty, P. F., \& Sawaya, R. J. (2014). One step forward: contrasting the effects of toe clipping and PIT tagging on frog survival and recapture probability. Ecology and Evolution, 4, 1480-1490.

Hastings, K. K., Hiby, L. A., \& Small, R. J. (2008). Evaluation of a computer-assisted photograph-matching system to monitor naturally marked harbor seals at Tugidak Island, Alaska. Journal of Mammalogy, 89, 1201-1211.

Kang, C., Kim, Y. E., \& Jang, Y. (2016). Colour and pattern change against visually heterogeneous backgrounds in the tree frog Hyla japonica. Scientific Reports, 6,22601

Kenyon, N., Phillott, A. D., Alford, R. A (2009). Evaluation of the photographic identification method (PIM) as a tool to identify adult Litoria Genimaculata (Anura: Hylidae). Herpetological Conservation and Biology, 4(3), 403-410.

Kim, J.Y. (2015). Lekking behavior in the Japanese treefrog Hyla japonica. Seoul, Republic of Korea: Ewha Womans University, p. 62.

Knox, C. D., Cree, A., Seddon, P. J (2012). Accurate identification of individual geckos (Naultinus gemmeus) through dorsal pattern differentiation. New zeal Journal of Ecology, 37, 60-66.

Lama, F. D., Rocha, M. D., Andrade, M. Â., \& Nascimento, L. B. (2011). The use of photography to identify individual tree frogs by their natural marks. $\mathrm{S}$ am. Journal of Herpetology, 6, 198-204.

Lemckert, F. (1996). Effects of toe-clipping on the survival and behaviour of the Australian frog Crinia signifera. Amphibia-Reptilia, 17, 287-290.

Lukacs, P. M., \& Burnham, K. P. (2005). Research notes: estimating population size from DNA-based closed capture-recapture data incorporating genotyping error. Journal of Wildlife Management, 69, 396-403.

McDonald, D., Dutton, P., Brander, R., Basford, S (1996). Use of pineal spot (pink spot) photographs to identify leatherback turtles. Herpetol Rev, 27, 11-11.

Roh, G., Borzée, A., \& Jang, Y. (2014). Spatiotemporal distributions and habitat characteristics of the endangered treefrog, Hyla suweonensis, in relation to sympatric H. japonica. Ecological Informatics, 24, 78-84. 
Stuart, S. N., Chanson, J. S., Cox, N. A., Young, B. E., Rodrigues, A. S., Fischman, D. L., \& Waller, R. W. (2004). Status and trends of amphibian declines and extinctions worldwide. Science, 306, 1783-1786.

Waddle, J. H., Rice, K. G., Mazzotti, F. J., \& Percival, H. F. (2008). Modeling the effect of toe clipping on treefrog survival: beyond the return rate. Journal of Herpetology, 42, 467-473.

Waichman, A. V. (1992). An alphanumeric code for toe clipping amphibians and reptiles. Herpetol Rev., 23(1), 19-21.

Wake, D. B. (2012). Facing extinction in real time. Science, 335, 1052-1053.

Yoshizaki, J., Pollock, K. H., Brownie, C., \& Webster, R. A. (2009). Modeling misidentification errors in capture-recapture studies using photographic identification of evolving marks. Ecology, 90, 3-9.

Submit your next manuscript to BioMed Central and we will help you at every step:

- We accept pre-submission inquiries

- Our selector tool helps you to find the most relevant journal

- We provide round the clock customer support

- Convenient online submission

- Thorough peer review

- Inclusion in PubMed and all major indexing services

- Maximum visibility for your research

Submit your manuscript at www.biomedcentral.com/submit
Biomed Central 